\title{
Outcomes of Decompressive Craniectomy for Spontaneous Deep Supratentorial Intracerebral Hemorrhage
}

\author{
ISLAM ABOUL-FETOUH, M.D. and ABD EL-AAL ABD EL-BAKY, M.D.
}

The Department of Neurosurgery, Faculty of Medicine, Benha University, Egypt

\begin{abstract}
Background: Spontaneous Intracerebral Hemorrhage (ICH) is one of the most devastating forms of cerebrovascular disease and is associated with high mortality and morbidity rate. Mass-effects of hematoma and surrounding edema lead to increase intracranial pressure and subsequent brain herniation. Decompressive Craniectomy (DC) provide space for the edematous brain to expand away from the midline structures and reduce intracranial pressure.
\end{abstract}

Aim of Study: The aim of this study was to evaluate the outcome of Outcomes of Decompressive Craniectomy for Spontaneous Deep Supratentorial Intracerebral Hemorrhage.

Patient and Methods: We retrospectively reviewed the medical records of the patients with spontaneous deep supratentorial ICH who underwent DC without evacuation of hematoma within 24 hour of ictus. Outcome was assessed by the Glasgow Outcome Scale (GOS) 6 months after surgery.

Results: A total of 12 patients were included in this study. The mean age was 45 years. Mean pre-operative Glasgow Coma Scale (GCS) score was 6.7. Mean hematoma volume was $68 \mathrm{ml}$. At 6 months after surgery, 8 patients $(67 \%)$ had favorable outcome while $4(33 \%)$ had unfavorable outcome 2 patients $(17 \%)$ died. $83 \%$ of patients with pre-operative GCS score $8-9$ compared to $50 \%$ with pre-operative GCS score 5-7 had favorable outcome. $71 \%$ of patients with hematoma volume less than or equal to $70 \mathrm{ml}$ compared with $60 \%$ with hematoma volume more than $70 \mathrm{ml}$ had favorable outcome.

Conclusions: Decompressive craniectomy can be beneficial in treatment of spontaneous deep supratentorial ICH in selected patient group. Patients with high pre-operative GCS score and small hematoma volume are more likely to have favorable outcome.

Key Words: Intracerebral hemorrhage-Decompressive craniectomy-Outcome.

\section{Introduction}

SPONTANEOUS intracerebral hemorrhage is one of the most devastating forms of cerebrovascular disease and is associated with high mortality and

Correspondence to: Dr. Islam Aboul-Fetouh, E-Mail: islamfetoh@hotmail.com morbidity rate [1-3]. ICH has been shown to be a dynamic process. Haemorrhagecontinue to expand over several hours after the onset of ictus. Their expansion is due to continued bleeding from the primary source and to the mechanical disruption of surrounding blood vessels [4,5]. Extravasated blood components trigger inflammatory changes that lead to edema and secondary damage of brain cells [6]

Mass-effects of hematoma and surrounding edema lead to increase intracranial pressure and subsequent brain herniation [7,8]. Decompressive craniectomy provide space for the edematous brain to expand away from the midline structures, prevent herniation, reduce intracranial pressure and improve cerebral perfusion [9]. Most of published studies focused on the role of DC with hematoma evacuation in treatment of ICH. In this study we assess the outcome of DC without hematoma evacuation in treatment of Spontaneous deep supratentorial ICH.

\section{Patients and Methods}

We retrospectively reviewed the medical records of the patients with spontaneous deeply seated supratentorial $\mathrm{ICH}$ who underwent DC without evacuation of hematoma within 24 hour of ictus in central hospitals of Ministry of Health in Saudi Arabia from January 2015 to January 2017 Figs. $(1,2)$. Data included patient demographic, clinical presentation, radiological studies and operative reports. Volume of hematoma was calculated using the $\mathrm{ABC} / 2$ method, [10] A was the greatest diameter of hemorrhage, B was the largest perpendicular diameter to $\mathrm{A}$ and $\mathrm{C}$ was the sum of the thickness of slices containing the hemorrhage. Patients with hemorrhage due to trauma, ruptured aneurysm, arteriovenous malformation, tumor or use of anticoagulants were excluded. 
Outcome was assessed by the Glasgow outcome scale 6 months after surgery. The outcome was considered favorable when the patient has good recovery or moderate disability. All other categories of GOS (severe disability, vegetative state, death) were considered as unfavorable outcome.
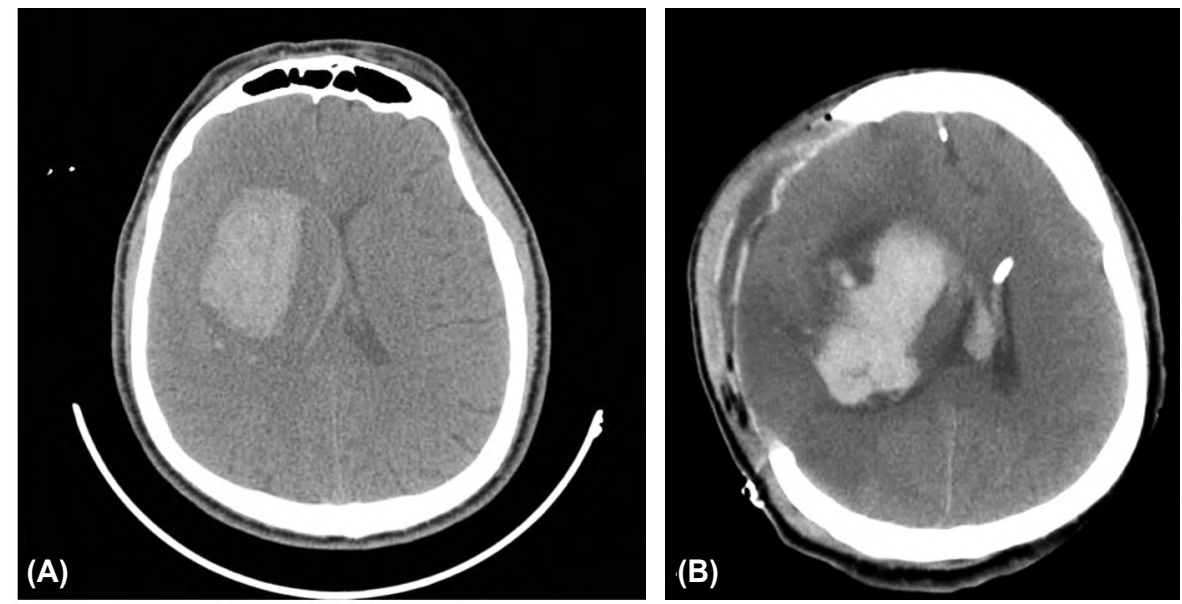

Fig. (1): 48 year's old male. (A) Pre-operative CT brain showed right deep cerebral and intraventricular hemorrhage. (B) CT brain post-decompressive craniectomy and insertion of external ventricular drain.
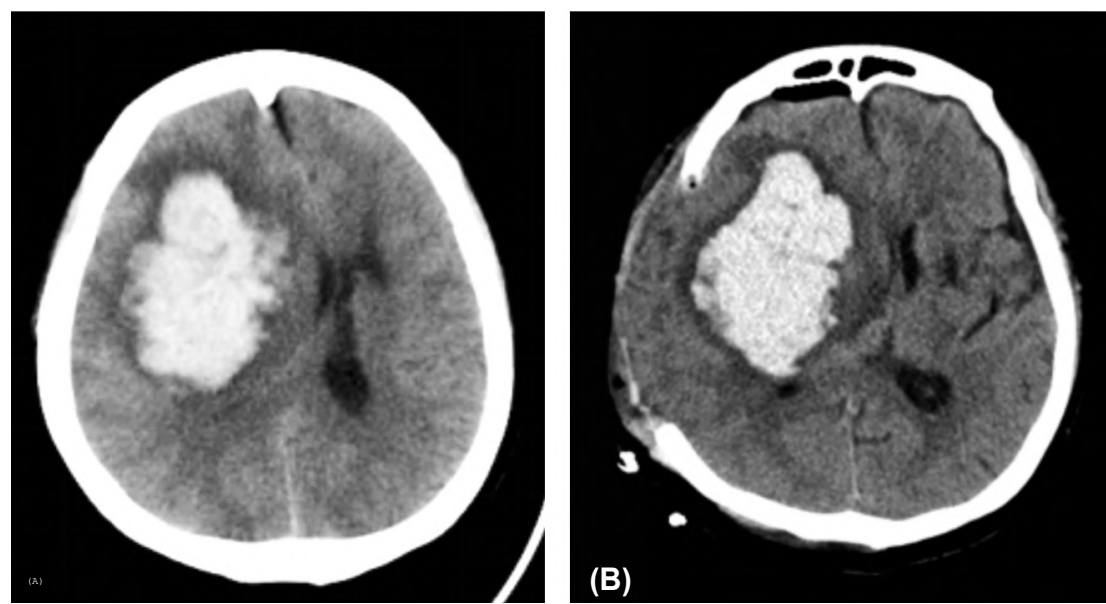

Fig. (2): 52 year's old male. (A) Pre-operative CT brain showed right deep cerebral hemorrhage.

(B) CT brain post-decompressive craniectomy .

\section{Results}

A total of 12 patients were included in this study. 10 patients were male and 2 were female. The mean age was 45 years (range $36-70$ years). 9 patients $(75 \%)$ were younger than 50 years. Mean pre-operative GCS score was 6.7 (range 5-9), six patients had a GCS score of 5-7 and the other 6 had a GCS score of 8-9. Hematoma was located in the right hemisphere in 8 patients and in the left hemisphere in 4 patients. Intraventricular hemorrhage was present in 4 patients. Mean hematoma volume was $68 \mathrm{ml}$ (rang $38-104 \mathrm{ml}$ ). It was less than or equal to $70 \mathrm{ml}$ in 7 patients and more than $70 \mathrm{ml}$ in 5 patients (Table 1). External ventricular drain was inserted in 3 patients. Two patients developed hydrocephalus and were treated with ventriculo-pertonial shunt.
Table (1): Patient data.

\begin{tabular}{lc}
\hline Patients data & Number of patients \% \\
\hline Gender: & $10(83 \%)$ \\
Male & $2(17 \%)$ \\
Female & \\
Pre-opetative GCS: & $6(50 \%)$ \\
$5-7$ & $6(50 \%)$ \\
$8-9$ & \\
Side of hematoma: & $8(67 \%)$ \\
Right & $4(33 \%)$ \\
Left & \\
Volume of hematoma: & $7(58 \%)$ \\
>70ml & $5(42 \%)$ \\
>70ml & \\
Outcome: & $8(67 \%)$ \\
Favorable & $4(33 \%)$ \\
Unfavorable &
\end{tabular}


At 6 months after surgery, 8 patients $(67 \%)$ had favorable outcome while $4(33 \%)$ had unfavorable outcome. Two patients $(17 \%)$ died. Five patients $(83 \%)$ with pre-operative GCS score 8-9 compared to 3 patients $(50 \%)$ with pre-operative GCS score 5-7 had favorable outcome Fig. (3). Five patients $(71 \%)$ with hematoma volume less than or equal to $70 \mathrm{ml}$ had favorable outcome and $2(29 \%)$ had unfavorable outcome. Three patients $(60 \%)$ with hematoma volume more than $70 \mathrm{ml}$ had favorable outcome and $2(40 \%)$ had unfavorable outcome Fig. (4).

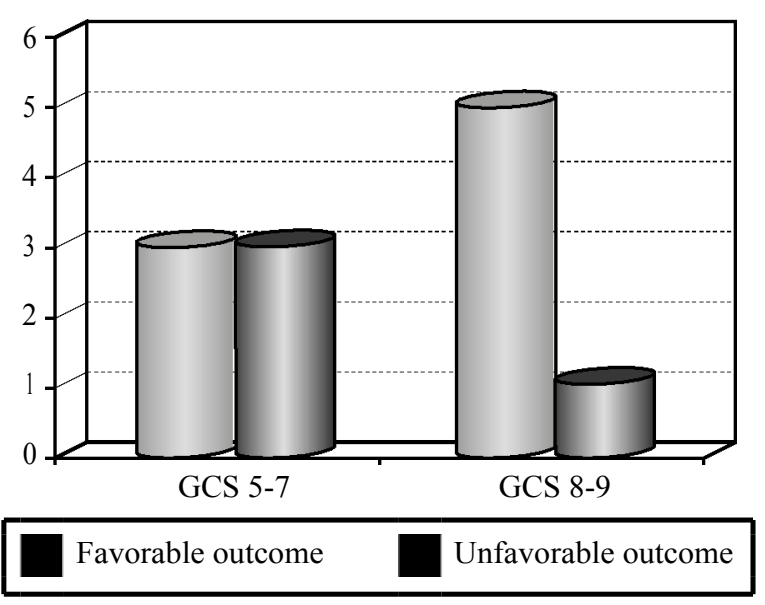

Fig. (3): Pre-operative GCS score and outcome.

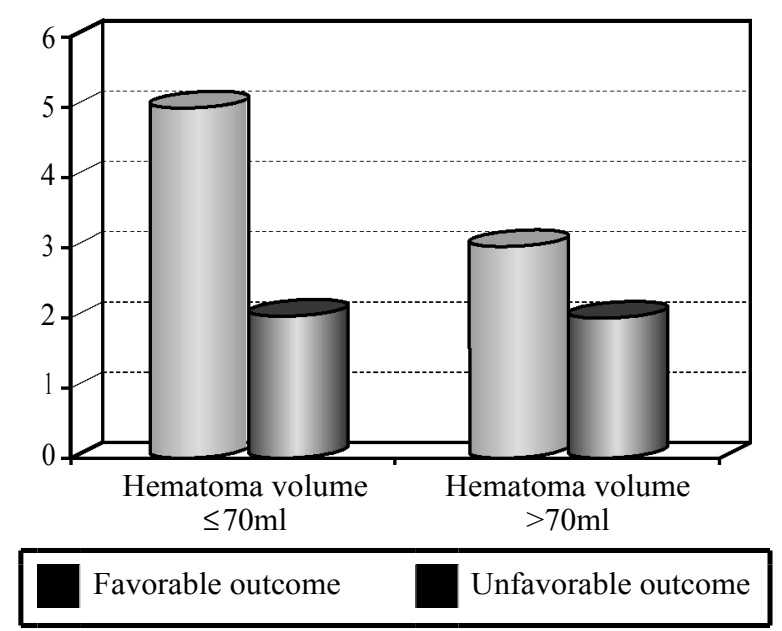

Fig. (4): Pre-operative hematoma volume and outcome.

\section{Discussion}

DC without hematoma evacuation showed a trend towards good outcome and reduced mortality as compared to matched controls in several recent studies [11-13]. Satter et al., [12] did a comparison study between DC and conservative treatment of spontaneous supratentorial ICH. $60 \%$ of patients had good outcome in surgical group compared to $52.5 \%$ of patients in conservative group. They indicates that DC is feasible and safe and can be a useful alternative surgical procedure in the treatment of spontaneous supratentorial ICH. In a case control study of DC in spontaneous supratentorial ICH by Lo et al., [13] survival rate in the craniectomy group was significantly higher compared with the medical treatment group at one, 6 and 12 months.

The main advantage of DC over hematoma evacuation is redaction of ICP with preservation of brain integrity especially in cases of ICH in dominant hemisphere [14] . Joarder et al., [15] compared patients with supratentorial ICH treated with DC without hematoma evacuation and craniotomy with hematoma evacuation. In the DC group, $66 \%$ of patients had good outcome and mortality was $26 \%$ while in hematoma evacuation group, $41 \%$ of patients had good outcome and mortality was $41 \%$. The authors concluded that DC is more effective than hematoma evacuation in patients with supratentorial ICH. Joarder et al., [14] studied 8 patients with hypertensive basal ganglionic hemorrhagetreated with DC without hematoma evacuation. Mean age was 58 years, mean hematoma volume was $58 \mathrm{ml}, 5$ patients $(62 \%)$ had good outcome and 2 patients (25\%) died. In our study $67 \%$ of patients had favorable outcome and mortality rate was $17 \%$. This good outcome could be explained by younger age of patients included in our study.

Many studies reported that, pre-operative hematoma volume and GCS score are important predictors of the outcome of ICH [16-18] . Ramnarayan et al., [16] studied the impact of DC in putaminal hematomas, they compared the outcome with GCS score on admission and volume of hematoma. Good outcome was $75 \%$ with GCS score $13-15,58 \%$ with GCS score $9-12$ and $43 \%$ with GCS score 3-8. As regard hematoma volume, good outcome was $67 \%$ when volume of hematoma was less than $30 \mathrm{ml}, 69 \%$ when it was $30-60 \mathrm{ml}$ and $29 \%$ when it was more than $60 \mathrm{ml}$. Similarly in our study, patients with pre-operative GCS score 8-9 and hematoma volume less than or equal to $70 \mathrm{ml}$ had better outcome when compared to patients with with GCS score 5-7 and hematoma volume more than $70 \mathrm{ml}$.

\section{Conclusions:}

Decompressive craniectomy can be beneficial in treatment of spontaneous deep supratentorial hemorrhage in selected patient group. Patients with high pre-operative GCS score and small hematoma volume are more likely to have favorable outcome. 


\section{References}

1- FEIGIN V.L., LAWES C.M., BENNETT D.A., BARKERCOLLO S.L. and PARAG V.: Worldwide stroke incidence and early case fatality reported in 56 population-based studies: A systematic review. Lancet Neurol., 8: 355-69, 2009.

2- HEUTS S.G., BRUCE S.S., ZACHARIA B.E., HICKMAN Z.L., KELLNER C.P., SUSSMAN E.S., McDOWELL M.M., BRUCE R.A. and CONNOLLY JR. E.S.: Decompressive hemicraniectomy without clot evacuation in dominant-sided intracerebral hemorrhage with ICP crisis. Neurosurgical focus, May, 34 (5): E4, 2013.

3- MAGISTRIS F., BAZAK S. and MARTIN J.: Intracerebral hemorrhage: Pathophysiology, diagnosis and management. MUMJ, 10 (1): 15-22, 2013.

4- MAYER S.A. and RINCON F.: Treatment of intracerebral haemorrhage. Lancet Neurol., 4: 662-72, 2005.

5- QURESHI A.I., TUHRIM S., BRODERICK J.P., BATJER H.H., HONDO H. and HANLEY D.F.: Spontaneous intracerebral hemorrhage. N. Engl. J. Med., 344 (19): 145060, 2001.

6- STEINER T. and BÖSEL J.: Options to restrict hematoma expansion after spontaneous intracerebral hemorrhage. Stroke, Feb. 1, 41 (2): 402-9, 2010.

7- ARIMA H., WANG J.G., HUANG Y., et al.: Significance of perihematomal edema in acute intracerebral hemorrhage: The INTERACT trial. Neurology, 73: 1963-8, 2009.

8- YANG J., ARIMA H., WU G., et al.: Prognostic significance of perihematomal edema in acute intracerebral hemorrhage: Pooled analysis from the intensive blood pressure reduction in acute cerebral hemorrhage trial studies. Stroke, 46: 1009-13, 2015.

9- TAKEUCHI S., WADA K., NAGATANI K., OTANI N. and MORI K.: Decompressive hemicraniectomy for spontaneous intracerebral hemorrhage. Neurosurgical focus, May, 34 (5): E5, 2013.

10- KOTHARI R.U., BROTT T., BRODERICK J.P., BARSAN W.G., SAUERBECK L.R., ZUCCARELLO M. and KHOURY J.: The ABCs of measuring intracerebral hemorrhage volumes. Stroke, Aug. 1, 27 (8): 1304-5, 1996.
11- FUNG C., MUREK M., Z'GRAGGEN W.J., KRÄHENBÜHL A.K., GAUTSCHI O.P., SCHUCHT P., GRALLA J., SCHALLER K., ARNOLD M., FISCHER U. and MATTLE H.P.: Decompressive hemicraniectomy in patients with supratentorial intracerebral hemorrhage. Stroke, Dec. 1, 43 (12): 3207-11, 2012.

12- SATTER A.R., ISLAM M.R., HAQUE M.R., MAHMOOD E., RAHMAN M.Z., BARMAN N. and RAHMAN M.A.: Comparison between Decompressive Craniectomy with Durotomy and Conservative Treatment in Spontaneous Supratentorial Intracerebral Hemorrhage. Mymensingh Medical Journal: M.M.J., Apr., 25 (2): 31625, 2016.

13- LO Y.T., SEE A.A. and KING N.K.: Decompressive craniectomy in spontaneous intracerebral hemorrhage: A case-control study. World Neurosurgery, Jul. 1, 103: 81520, 2017.

14- JOARDER M.A., KARIM A.B., SUJON S.I., AKHTER N., WAHEEDUZZAMAN M., SHANKAR D.R., JAHANGIR S.M. and CHANDY M.J.: Decompressive Hemicraniectomy in Hypertensive Basal Ganglia Hemor rhages. Pulse, Jun. 6, 8 (1): 38-42, 2016.

15- JOARDER M.A., KARIM A.K., KAMAL T., SUJON T., AKHTER N., ISLAM K., HOSSAIN M.Z., MOLLIK A., SULTANA S., SHANKAR D.R. and JAHANGIR S.M.: Retrospective comparison of decompressive hemicraniectomy and hematoma evacuation for spontaneous supratentorial intracerebral hematoma. Pulse, May 7, 7 (1): 1621, 2015.

16- RAMNARAYAN R., ANTO D., ANILKUMAR T.V. and NAYAR R.: Decompressive hemicraniectomy in large putaminal hematomas: An Indian experience. Journal of Stroke and Cerebrovascular Diseases, Jan 1, 18 (1): 1-0, 2009.

17- REHMAN W.A. and ANWAR M.S.: Surgical outcome of spontaneous supra tentorial intracerebral hemorrhage. Pakistan Journal of Medical Sciences, Jul., 33 (4): 804, 2017.

18- HOSSAIN M., AHMED S., ANSARY S. and ISLAM S.: Surgical Outcome Of Spontaneous Intracerebral Haematoma Through Keyhole Craniectomy. Faridpur. Med. Coll. J., 5 (2): 60-2, 2010. 


\section{نتائج جراحات إزالة عظام الجمجمة

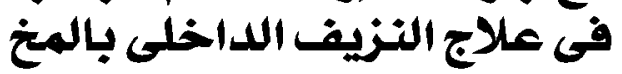

المقدمة: يعد النزيف من آكثر آمراض المخ خطودة وعادة ما يكن مصحوب بنسبة عالية من المضاعفات والوفيات. يؤدى النزيف داخل

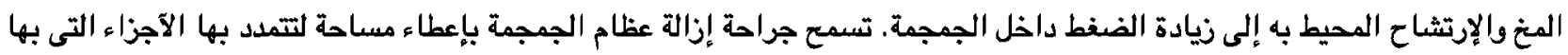
إرتثاح بالمخ وبذالك تخفف الضغط على منتصف المخ وتقلل الضغط داخل المل الجمجمة.

طريقة البحث: تم مراجعة السجلات الطبية الخاصة بالمرضى الذين كانوا يعانوا من نزيف داخل المخ وتم إجراء جراحة لإزالة عظام

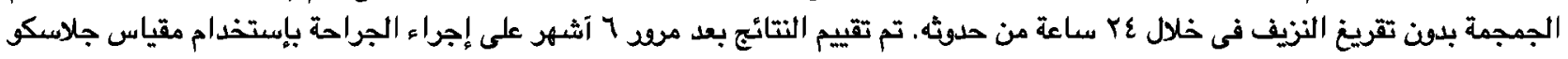

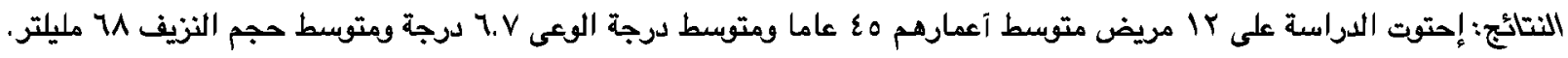

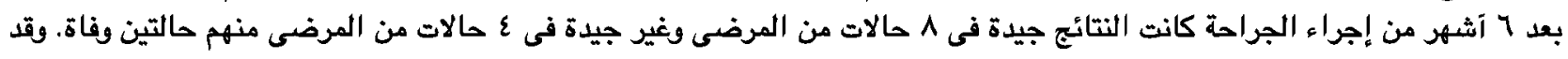

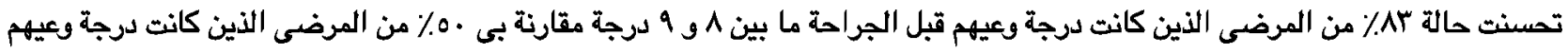

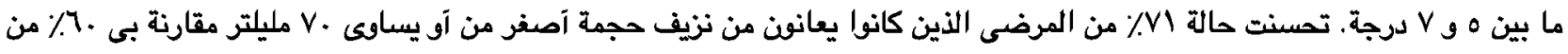

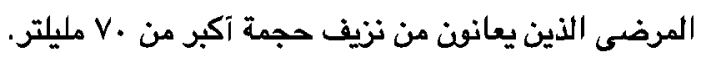

الإستتاج: تعد جراحة إزالة عظام الجمجمة مفيدة لبعض المرضى الذين يعانون من نزيف داخل المخ. غالبا ما تكن النتائج جيدة فى في

حالات المرضى ذات درجة وعى مرتفع قبل الجراحة وذات حجم صغير اللنزيف. 